\title{
Uptodate in Deep Vein Thrombosis
}

\author{
Destefani $\mathrm{AC}^{1 *}$ and Taufner $\mathrm{GH}^{2}$ \\ ${ }^{1}$ Department of Biomedical Sciences, Federal University of Espírito Santo, Brazil \\ ${ }^{2}$ Department of Biotechnology, Federal University of Espírito Santo, Brazil
}

Submission: February 11, 2017; Published: March 23, 2017

* Corresponding author: Afrânio Côgo Destefani, Professor of the Biomedicine Course of the Faculty of Biomedical Sciences of Espírito Santo, Rua Bolivar de Abreu, 48, Campo Grande, Cariacica/ES, Zip code: 29.146-330, Brazil, Email: afraniocd@gmail.com

Abstract

Venous thrombosis is a condition in which a blood coagulation (thrombus) shapes in a vein. This coagulation can constrain blood course through the vein, bringing on swelling and torment. Most normally, venous thrombosis happens in the "profound veins" in the legs, thighs, or pelvis; this is known as a deep vein thrombosis, or DVT. DVT is the most well-known kind of venous thrombosis. Be that as it may, a thrombus can shape anyplace in the venous framework. On the off chance that a section or the greater part of the blood coagulation in the vein severs from the site where it is shaped, it can go through the venous framework; this is called an embolus.

In the event that the embolus holds up in the lung, it is called pulmonary embolism (PE), a genuine condition that prompts to more than 50,000 passing's a year in the United States. Much of the time, PE is brought on when part of a DVT severs and cabins in the lung. The expression "venous thromboembolism" is now and then utilized while talking about both DVT and PE. This review talks about the hazard variables, signs and manifestations, demonstrative process, and treatment of a profound vein thrombosis. The determination and treatment of pneumonic embolisms are talked about independently.

Keywords: Deep vein thrombosis; Pulmonary embolism; Venous thrombo embolism; Prophylaxis; Treatment

\section{Introduction}

There are various elements that expansion a man's danger of building up a profound vein thrombosis. On the off chance that a man is found to have a DVT and there is no known therapeutic condition or late surgery that could have brought on the DVT, it is conceivable that an acquired condition is the cause. This is particularly valid in individuals with a relative who has likewise encountered a DVT or pneumonic embolism. In these cases, testing for an acquired thrombophilia might be prescribed. In any case, finding an acquired thrombophilia does not change the way that specialists treat the venous thromboembolism, and may not build the shot of the blood coagulation returning.

\section{Restorative conditions or solutions}

Some therapeutic conditions and medicines increment a man's danger of building up a blood coagulation: Pregnancy; Obesity; Smoking; Heart disappointment; Previous DVT or pneumonic embolism (PE); Increased age; Cancer-Some malignancies increment substances in the blood that make blood cluster; Kidney issues, for example, nephrotic disorder; Certain drugs (e.g., some conception prevention pills, hormone substitution treatment, erythropoietin, tamoxifen, thalidomide). The danger of a blood coagulation is further expanded in individuals who utilize one of these pharmaceuticals, and furthermore have other hazard elements.

\section{Surgery and related conditions}

Surgical methods, particularly those including the hip, pelvis, knee, mind, or spine, and also injury (particularly if veins are harmed) increment a man's danger of building up a blood coagulation. Amid the recuperation time frame, this hazard frequently proceeds in light of the fact that the individual is less dynamic. Dormancy amid long treks can likewise expand a man's danger of building up a blood coagulation. Safeguards to decrease the danger of blood clusters are examined beneath.

\section{Gained thrombophilia}

Some sorts of thrombophilia are not acquired, but rather can in any case increment a man's danger of building up a blood coagulation. Certain disarranges of the blood, for example, polycythemia vera or fundamental thrombocythemia; 
Antiphospholipid (antibodies in the blood that can influence the thickening procedure).

\section{Acquired thrombophilia}

Inherited thrombophilia alludes to a hereditary issue that causes the blood to cluster more effectively than typical. Different considers the blood thickening procedure might be included, contingent upon the sort of hereditary issue introduce. An acquired thrombophilia is every so often exhibit in individuals with a venous blood cluster (i.e., thrombus).

For instance, insufficiencies of antithrombin, protein $\mathrm{C}$, or protein $\mathrm{S}$ can be found in under 5 percent of patients who have had an unjustifiable venous blood clump (blood coagulation not brought about by a therapeutic or surgical condition). Different components, for example, figure $\mathrm{V}$ Leiden or the prothrombin quality change, can happen in roughly 20 to 25 percent of individuals with a venous blood clump. Nonetheless, calculate $\mathrm{V}$ Leiden or the prothrombin quality change is likewise found in up to 5 percent of generally sound Caucasians. Venous thrombosis is occasional before puberty in individuals with acquired thrombophilia.

\section{Dvt Symptoms}

The signs and indications of DVT might be brought on by a coagulation, or might be identified with another condition. Imaging studies are expected to figure out whether a coagulation is available.

a) Profound vein thrombosis-Classic manifestations of DVT incorporate swelling, agony, warmth, and redness in the included leg.

b) Shallow phlebitis-Superficial phlebitis (SP) causes torment, delicacy, solidness, as well as redness in a vein because of aggravation, disease, or potentially a blood coagulation (thrombus). It is most normally found in the internal part of the lower legs.

Shallow phlebitis varies from a profound vein thrombosis in light of the fact that the veins that are influenced are close to the surface of the skin. Side effects of SP normally create over hours to days and resolve in days to weeks. The zone may keep on being firm for a little while to months. Treatment generally incorporates warm or cool packs, height of the leg, a nonsteroidal mitigating operator (NSAID, for example, ibuprofen (Advil, Motrin), or anticoagulation. In a great many people with SP, there is an okay of building up a DVT or aspiratory embolism, so anticoagulation is not generally required

\section{Dvt Diagnosis}

In the event that the patient's history, manifestations, and physical exam propose a DVT, tests are expected to affirm this. Tests to analyze DVT may incorporate pressure ultrasonography, differentiate venography, attractive reverberation imaging (MRI), figured tomography (CT check), or potentially a blood test called D-dimer. In the event that a man with a DVT likewise has signs or side effects of a pneumonic embolus, extra testing will be required.

\section{D-dimer}

D-dimer is a substance in the blood that is frequently expanded in individuals with DVT or pneumonic embolism (PE). D-dimer testing is at times helpful for patients with a suspected DVT or PE. On the off chance that the D-dimer test is negative and the patient has a generally safe of DVT or PE based upon his/ her history and physical examination, DVT or PE are improbable and facilitate symptomatic testing may not be required.

\section{Pressure ultrasonography}

Compression ultrasonography utilizes sound waves to create photos of the structures inside the leg. For this sort of exam, a man lies on his/her back and afterward stomach as a ultrasound wand is connected to the leg. Much of the time, pressure ultrasonography is the trial of decision for patients with suspected DVT.

\section{Differentiate venography}

During difference venography, a catheter is strung into a vein and a color is infused. This permits the clinician to see the vein with $\mathrm{x}$-beam. Venography is by and large saved for circumstances in which ultrasound is impossible, when different tests have not been useful, or when different tests are negative however the clinician feels unequivocally that a venous thrombosis is available.

\section{Attractive reverberation imaging (MRI)}

MRI utilizes a solid magnet to create point by point photos of within the body. X-ray is as exact as difference venography. $\mathrm{X}$-ray is costly, and its utilization might be constrained to circumstances in which differentiate venography can't be performed, for example, in patients with poor kidney work, amid pregnancy, or due to sensitivity to the color required conversely venography.

\section{Finding the reason for venous thrombosis}

After establishing that DVT or PE is available, the human services supplier will need to recognize what created it. As a rule, there are clear hazard variables, for example, late surgery or fixed. In different cases, the clinician may test for the nearness of an acquired type of thrombophilia or for another medicinal condition related with an expanded hazard for venous thrombosis.

People with some procured or acquired irregularities may require extra treatment or counteractive action measures to lessen the danger of another thrombosis. A few specialists prescribe that the relatives of a man with an acquired thrombophilia be screened for the acquired condition if this data would influence their care too, in spite of the fact that this issue is disputable. It is essential that the medicinal services supplier 
talks about the advantages and disadvantages of screening for an acquired thrombophilia with the patient before this testing is finished.

\section{Dvt Treatment}

The treatment of DVT and pneumonic embolism (PE) are comparable. In DVT, the principle objective of treatment is to keep a PE. Different objectives of treatment incorporate keeping the coagulation from getting to be distinctly bigger, keeping fresh recruits clumps from shaping, and averting long haul confusions of PE or DVT. The essential treatment for venous thrombosis is anticoagulation. Other accessible medicines, which might be utilized as a part of particular circumstances, incorporate thrombolytic treatment or putting a channel in a noteworthy vein (the substandard vena cava).

\section{Anticoagulation}

Anticoagulants are pharmaceuticals that are generally called «blood thinners.» They don't really break down the coagulation, but instead help to keep fresh recruits clusters from shaping. There are a few unique medicines that may be given after a DVT analysis (alluded to as «introductory anticoagulation»), including: Low atomic weight heparin, which is given as an infusion under the skin-Options incorporate enoxaparin (mark name: Lovenox), dalteparin (mark name: Fragmin), and tinzaparin (mark name: Innohep). Fondaparinux (mark name: Arixtra), likewise given by infusion; Unfractionated heparin, which is given into a vein (intravenously) - This might be the favored decision in specific conditions, for example, if the patient has extreme kidney disappointment or precarious pulse.

\section{Direct oral anticoagulants}

These are accessible in pill shape; they incorporate rivaroxaban (mark name: Xarelto) and apixaban (mark name: Eliquis).

Starting anticoagulation is proceeded for 5 to 10 days. From that point onward, long haul anticoagulation is proceeded for 3 to 12 months (see 'Length of treatment' underneath). By and large, the immediate oral anticoagulants are the favored decision for long haul anticoagulation; these pills incorporate rivaroxaban (mark name: Xarelto), apixaban (mark name: Eliquis), dabigatran (mark name: Pradaxa), and edoxaban (mark name: Savaysa). In a few circumstances, another oral drug called warfarin (test mark name: Coumadin) is given. For patients taking warfarin, the thickening elements in the blood should be measured all the time with a blood test called the International Normalized Ratio (INR), while this is not required for patients on direct oral anticoagulants. Less normally, the patient does not take warfarin or any of the immediate oral anticoagulants however takes an everyday infusion of low atomic weight heparin or fondaparinux for the whole treatment time frame.

The decision of anticoagulant relies on various variables, including the inclination of the patient and the human services supplier, the patient's restorative history and different conditions, and cost contemplations.

\section{Term of treatment}

Anticoagulation is prescribed for a minimum of three months in a patient with DVT. In patients who had a reversible hazard consider adding to their DVT, for example, injury, surgery, or being kept to bed for a delayed period, the individual is regularly treated with anticoagulation for three months or until the hazard element is settled.

Expert bunches recommend that individuals who build up a venous thrombosis and who don't have a known hazard figure for thrombosis may require treatment with an anticoagulant for an uncertain timeframe [1]. In any case, this choice ought to be talked about with the individual's human services supplier following three months of treatment, and afterward reassessed all the time. A few people want to proceed with the anticoagulant, which may convey an expanded danger of dying, while others want to stop the anticoagulant sooner or later, which may convey an expanded hazard for rehash thrombosis.

Most specialists prescribe proceeding with anticoagulation inconclusively for individuals with at least two scenes of venous thrombosis or if a lasting danger calculate for thickening is available (e.g., antiphospholipid disorder, malignancy).

\section{Strolling amid DVT treatment}

Once an anticoagulant has been begun and indications (eg, torment, swelling) are under control, the individual is unequivocally urged to get up and stroll around. Contemplates demonstrate that there is no expanded danger of inconveniences (eg, pneumonic embolus) in individuals who get up and walk, and strolling may in reality help the individual feel better speedier.

\section{Thrombolytic treatment}

At times, a social insurance supplier will prescribe an intravenous pharmaceutical to break down blood clumps. This is called thrombolytic treatment. This treatment is saved for patients who have genuine complexities identified with PE or DVT, and who have a generally safe of genuine seeping as a reaction of the treatment. The reaction to thrombolytic treatment is best when there is a brief span between the finding of DVT/PE and the begin of thrombolytic treatment.

\section{Inferior vena cava filter}

Inferior vena cava (IVC) filter is a gadget that obstructs the dissemination of clusters in the circulatory system. It is put in the sub-par vena cava (the vast vein driving from the lower body to the heart). The IVC channel normally is embedded through a little cut in a leg vein with the utilization of a nearby analgesic and takes 20 to 30 minutes to perform. An IVC channel is frequently suggested in patients with venous thromboembolism who can't utilize anticoagulants in view of a high draining danger. In any case, in the long haul, IVC channels can expand the danger of creating blood clumps. 


\section{Dvt Prevention}

\section{Surgical patients}

Certain high hazard patients experiencing surgery (particularly bone or joint surgery and tumor surgery) might be offered anticoagulants to diminish the danger of blood clusters. Anticoagulants may likewise be given to ladies at high hazard for venous thrombosis amid and after pregnancy.

In surgical patients with a direct to generally safe of blood clumps, other preventive measures might be utilized. For instance, some surgical patients are fitted with inflatable pressure gadgets that are worn around the legs amid and instantly after surgery and occasionally load with air. These gadgets apply tender weight to enhance course and help avoid clusters.

Graduated pressure leggings may likewise be prescribed; these tights apply weight to the lower legs, with the best weight at the lower leg. The weight bit by bit diminishes up to the knee. For all patients, strolling as quickly as time permits after surgery can diminish the danger of a blood coagulation.

\section{Amplified travel}

Prolonged travel seems to present a two-to fourfold increment in danger of venous thromboembolism (VTE) [2]. There are a couple tips that might be of advantage amid augmented travel.

\section{Exceptional Precautions for People with Dvt}

\section{Second thrombosis}

Patients being dealt with for venous thrombosis are at an expanded hazard for building up another blood coagulation, in spite of the fact that this hazard is fundamentally littler when an anticoagulant is utilized. The patient ought to look for new leg torment, swelling, or potentially redness. In the event that these manifestations happen, the patient ought to address his/her medicinal services supplier or look for restorative consideration as quickly as time permits [3].

Different side effects may show that a coagulation in the leg has severed and made a trip to the lung, bringing on a pneumonic embolism. These may include: New trunk torment with trouble relaxing; A fast heart rate as well as a sentiment going out This intricacy might be life-undermining and requires quick consideration. Crisis medicinal administrations are accessible in many zones of the United States by calling 911.

\section{Dying}

Anticoagulants, for example, heparin and warfarin can have genuine reactions and ought to be taken precisely as coordinated. On the off chance that a measurement is overlooked, the patient ought to call his/her social insurance supplier or facility for counsel. The measurement ought not to be switched to compensate for missed dosages, unless the supplier or center guides the patient to do as such. Patients ought to quickly answer to the drug specialist or doctor if the pill or tablet looks not quite the same as the past jug. Different insurances are important when taking warfarin, and are sketched out in a different subject audit.

Patients may drain effectively while taking anticoagulants. Draining may create in numerous ranges, for example, the nose or gums, exorbitant menstrual dying, seeping in the pee or excrement, draining or over the top wounding in the skin, and regurgitating material that is splendid red or dull chestnut like espresso beans. Now and again, draining can create inside the body and not be seen instantly. Seeping inside the body can bring about a man to feel black out, or have torment in the back or belly. A human services supplier ought to be told instantly if there is any indication of this issue. A medicinal services supplier ought to likewise be advised quickly if the patient on anticoagulants maintained a damage that could prompt to seeping inside the body [4].

\section{Wear a ready tag}

People who take anticoagulants ought to wear a wristband, jewelry, or comparative ready tag at all circumstances. In the event that therapeutic treatment is required and the individual is too sick to clarify his/her condition, the tag will ready responders about the patient's utilization of anticoagulants and danger of unnecessary dying. The ready tag ought to list the individual's medicinal conditions, and additionally the name and telephone number of a crisis contact. One gadget, Medic Alert, gives a without toll number that crisis therapeutic laborers can get to discover a man's medicinal history, rundown of pharmaceuticals, family crisis contact numbers, and human services supplier names and numbers [5-8].

\section{Lessen the danger of dying}

Some basic changes can constrain the danger of dying: Use a delicate abound toothbrush; Shave with an electric razor instead of a sharp edge; Take mind when utilizing scissors or blades; Avoid conceivably hurtful exercises (e.g., contact sports); Use proper security hardware (e.g., caps, cushioning) amid physical movement; Do not take headache medicine or other non-steroidal mitigating operators (NSAIDS) (e.g., ibuprofen, Advil, Aleve, Motrin, Nuprin) unless coordinated to do as such by a social insurance supplier. Other nonprescription agony prescriptions, for example, acetaminophen, might be a sheltered option [9].

\section{References}

1. Kearon C, Akl EA, Comerota AJ, Prandoni P, Bounameaux H, et al. (2012) Antithrombotic therapy for VTE disease: Antithrombotic Therapy and Prevention of Thrombosis, 9th ed: American College of Chest Physicians Evidence-Based Clinical Practice Guidelines. Chest 141(2_suppl): e419S-e494S.

2. Kelman CW, Kortt MA, Becker NG, Li Z, Mathews JD, et al. (2003) Deep vein thrombosis and air travel: record linkage study. BMJ 327(7423): 1072. 
3. Chee YL, Watson HG (2005) Air travel and thrombosis. Br J Haematol 130(5): 671-680.

4. Martinelli I (2001) Risk factors in venous thromboembolism. Thromb Haemost 86(1): 395-403.

5. Hyers TM (1999) Venous thromboembolism. Am J Respir Crit Care Med 159(1): 1-14.

6. Qaseem A, Snow V, Barry P, Hornbake ER, Rodnick JE, et al. (2007) Current diagnosis of venous thromboembolism in primary care: a clinical practice guideline from the American Academy of Family Physicians and the American College of Physicians. Ann Intern Med 5(1): 57-62.

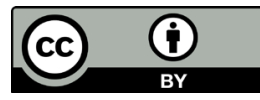

This work is licensed under Creative Commons Attribution 4.0 License

DOI: $10.19080 /$ JOCCT.2017.03.555622
7. Segal JB, Streiff MB, Hofmann LV, Thornton K, Bass EB, et al. (2007) Management of venous thromboembolism: a systematic review for a practice guideline. Ann Intern Med 146(3): 211-222.

8. Snow V, Qaseem A, Barry P, Hornbake ER, Rodnick JE, et al. (2007) Management of venous thromboembolism: a clinical practice guideline from the American College of Physicians and the American Academy of Family Physicians. Ann Fam Med 5(1): 74-80.

9. Blann AD, Lip GY (2006) Venous thromboembolism. BMJ 332(7535) 215-219.

\section{Your next submission with Juniper Publishers} will reach you the below assets

- Quality Editorial service

- Swift Peer Review

- Reprints availability

- E-prints Service

- Manuscript Podcast for convenient understanding

- Global attainment for your research

- Manuscript accessibility in different formats

( Pdf, E-pub, Full Text, Audio)

- Unceasing customer service

Track the below URL for one-step submission https://juniperpublishers.com/online-submission.php 